\title{
Septal Myocardial Infarction by ECG Finding
}

National Cancer Institute

\section{Source}

National Cancer Institute. Septal Myocardial Infarction by ECG Finding. NCI Thesaurus.

Code C35519.

An electrocardiographic finding suggesting an infarction in the anatomic location of the cardiac septum. 